\title{
O estágio não obrigatório na formação de licenciados em ciências biológicas: um espaço de possibilidade formativa
}

Jucilaine Araujo Bottega da Rocha Pinheiro araujojucilaine@gmail.com orcid.org/0000-0002-6414-8421 Universidade Federal da Fronteira Sul (UFFS), Realeza, Paraná, Brasil.

Barbara Grace Tobaldini de Lima barbara.lima@uffs.edu.br Universidade Federal da Fronteira Sul (UFFS), Realeza, Paraná, Brasil.

Sandra Maria Wirzbicki sandra.wirzbicki@uffs.edu.br $\frac{\frac{\text { orcid.org/0000-0001-8402-7099 }}{\text { Universidade Federal da Fronteira Sul }}}{\text { or }}$ (UFFS), Realeza, Paraná, Brasil.

Andréia Florêncio Eduardo de Deus andreia.eduardo@uffs.edu.br Universidade Federal da Fronteira Su (UFFS), Realeza, Paraná, Brasil.

\section{RESUMO}

A prática dos estágios supervisionados obrigatórios e não obrigatórios é uma ação presente em diversas áreas do conhecimento, e é o momento de assimilar as teorias aprendidas ao longo da formação com as práticas profissionais oportunizadas. Nesta pesquisa, a área em estudo, envolve a formação de licenciandos em Ciências Biológicas a partir de uma das inquietações oriundas do estágio não obrigatório - qual a contribuições dessa atividade na formação acadêmica e profissional dos participantes. Essa situação foi problematizada e discutida no desenvolvimento da pesquisa. Que teve como objetivo compreender como a prática de estágios não obrigatórios podem contribuir na formação acadêmica e profissional dos licenciandos em Ciências Biológicas. Nosso estudo, de caráter qualitativo e desenvolvido a partir das orientações do Estudo de Caso, e com análise a partir da Análise Textual Discursiva (ATD) identificou duas principais categorias. Na primeira a discussão envolve o perfil do licenciado em Ciências Biológicas e a segunda as contribuições do estágio não obrigatório para a formação dos participantes. Nossos resultados indicam similaridade com as contribuições historicamente construídas, na prática dos estágios obrigatórios, como também, que o estágio não obrigatório é espaço para problematizar o desenvolvimento dos saberes profissionais junto as atividades curriculares do curso de graduação. Finalizamos com argumentos sobre a necessidade de ampliar a discussão sobre a formação de professores junto aos formadores da instituição, sobre o espaço que o estágio ocupa na formação dos acadêmicos dos cursos de licenciatura, e por quais razões as Secretarias de Educação Municipal contratam acadêmicos de cursos que não habilitam formalmente para esse nível de ensino. Reflexões que entendemos ser necessárias para a qualificação acadêmica e profissional dos licenciandos.

PALAVRAS-CHAVE: Educação em Ciências. Formação de professores. Profissionalização docente. 


\section{INTRODUÇÃO}

Indagar, questionar e analisar a formação de licenciados é prática recorrente nas pesquisas educacionais. A partir delas é possível identificar lacunas e desafios envolvendo o processo de formação dos acadêmicos, mas também possibilidades e/ou potencialidades para o trabalho do formador e dos próprios discentes. Neste viés, o estágio curricular e as atividades realizadas a partir do Programa Institucional de Bolsas de Iniciação à Docência (PIBID) e, mais recentemente, o Programa Residência Pedagógica (PRP), são potenciais espaços de análise, reflexão e investigação dos saberes e práticas docentes. Ao reconhecer a importância desses espaços, nos questionamos sobre que outras atividades podem influenciar na formação dos licenciados e na prática do formador e, assim, no próprio projeto do curso e da instituição. Neste panorama de inquietações e possibilidades é que realizamos este trabalho.

Enquanto discente de um curso de Licenciatura em Ciências Biológicas, pedagoga e docentes de uma universidade pública sediada no Paraná, observamos que nas discussões das atividades desenvolvidas em sala de aula alguns acadêmicos relacionavam as temáticas trabalhadas com experiências oriundas das suas inserções em projetos de ensino, pesquisa e extensão, e outros com as atividades desenvolvidas a partir do estágio não obrigatório. Com essas situações, problematizamos como as atividades e experiências vivenciadas pelos acadêmicos podem influenciar nas suas discussões, no percurso formativo e nas escolhas profissionais. Das possibilidades a serem investigadas, optamos por desenvolver como Trabalho de Conclusão de Curso, de uma das autoras deste trabalho, uma investigação a respeito do estágio não obrigatório, e, para isso, nosso objetivo consistia em "Compreender como a prática de estágios não obrigatórios contribui na formação acadêmica e profissional dos licenciandos em Ciências Biológicas".

Para isso foi necessário: analisar a regulamentação dos estágios não obrigatórios no curso; conhecer quais são os envolvidos na prática de estágios não obrigatórios; relatar quais os objetivos dos participantes do estágio não obrigatório quanto à sua formação; identificar os principais espaços de inserção dos discentes nos estágios não obrigatórios; caracterizar as atividades desenvolvidas nos estágios não obrigatórios; e reconhecer as potencialidades, desafios e lacunas encontrados na prática dos estágios não obrigatórios. Essas ações caracterizam os objetivos específicos, mas também o encaminhamento teórico e metodológico adotado e mobilizado no desenvolvimento desta pesquisa.

Esses itens também organizam a fundamentação teórica marcada pelos aspectos históricos e legais a respeito dos estágios (obrigatório e não obrigatório) na formação de licenciandos e o diálogo com os documentos oficiais e pesquisas acadêmicas de âmbito nacional referente à temática. É importante salientar que, pelas ausências de trabalhos a respeito do estágio não obrigatório, os primeiros argumentos do referencial teórico estão concentrados na modalidade do estágio obrigatório em cursos de Licenciatura e, a partir deles, problematizamos os elementos que podem ajudar a compreender e caracterizar a modalidade de estágio não obrigatório. Na sequência alguns regulamentos de estágios das universidades públicas da Região Sul, são referenciados com o objetivo de compreender o cenário em que se encontra a prática do estágio não obrigatório nessas instituições. 
$\mathrm{Na}$ seção seguinte discorremos sobre os elementos da metodologia ao caracterizar o tipo de pesquisa que será realizada, os participantes, os instrumentos e a técnica para analisar o material obtido. Finalizamos este trabalho com os principais resultados, nossa interpretação, diálogo e inferências a respeito das atividades de estágio não obrigatório para o contexto de formação acadêmica e profissional daqueles que realizam essas atividades.

\section{OS ESTÁGIOS NA FORMAÇÃO DE PROFESSORES: PERSPECTIVAS HISTÓRICAS, LEGAIS E SUAS POSSIBILIDADES}

Historicamente, as atividades de estágio obrigatório estão presentes na formação de professores a partir da prática de ensino, como sinalizado por Pimenta (1995). Dentro desse contexto, o estágio era elemento fundamental na formação. Por volta dos anos 30 e 40 do século 20, a finalidade do ensino era promover a formação do docente necessária às escolas primárias, e a prática nesta conjuntura era inserida como imitação dos modelos teóricos existentes, bem como a observação de práticas consideradas bem-sucedidas (PIMENTA, 1995). Nessa perspectiva, o estágio obrigatório se reduzia à imitação de aulas modelos, sem que os estagiários pudessem articular e promover mudanças nas práticas escolares. Assim, as práticas de estágio obrigatório pouco propiciavam a articulação entre os saberes teóricos e práticos para a formação de professores, apesar disso "apresenta ao futuro professor a realidade do seu cotidiano de trabalho" (SANTOS; FREIRE, 2017, p. 265).

Nas últimas décadas com as produções acadêmicas e ações de formação de professores vivenciadas, compreendemos que é fundamental que durante a realização dos estágios obrigatórios os licenciandos busquem por outros conhecimentos. De acordo com Ghedin, Almeida e Leite (2008), com a promulgação da Lei de Diretrizes e Bases da Educação Nacional de 1996, novas políticas e legislações foram regulamentadas pelo Conselho Nacional de Educação (CNE) com o objetivo de orientar e organizar algumas das questões relativas à formação inicial de professores. Como parte desse processo, foram redigidas as Diretrizes Curriculares para os cursos de Graduação, entre elas para os cursos de Ciências Biológicas.

De acordo com o Parecer no CNE/CES 1.301/2001, que institui essa diretriz, a estrutura curricular do estágio é uma atividade obrigatória e supervisionada que contabiliza horas e créditos. Cita, ainda, que os estágios junto a outras atividades, têm como objetivo estimular a interação entre o domínio teórico e prático da formação.

Com a Resolução do CNE no 1, de 18 de fevereiro de 2002, no que se refere ao estágio supervisionado, na matriz curricular do curso de formação de professores, a prática não pode ficar reduzida a um espaço limitado e ser restringida apenas ao estágio desarticulado do restante do curso. Este movimento pode estar presente desde o início do curso e durante toda a formação acadêmica.

O estágio obrigatório, como campo de conhecimento indispensável à formação dos professores, é uma prática fundamental para construção da identidade profissional e dos saberes, e não pode ser conceituado somente como uma atividade burocrática e obrigatória para a formação. 0 objetivo central 
consiste em problematizar o aprendizado quanto ao ofício de ser professor, possibilitando um conhecimento da realidade do trabalho e das necessidades do ambiente escolar (GHEDIN; ALMEIDA; LEITE, 2008). O desenvolvimento das atividades de estágio, desde 2008, é regulamentado pela Lei no 11.788 , de 2008, que dispõe que o estágio dos estudantes é:

Art. 10 Estágio é ato educativo escolar supervisionado, desenvolvido no ambiente de trabalho, que visa à preparação para o trabalho produtivo de educandos que estejam frequentando o ensino regular em instituições de educação superior, de educação profissional, de ensino médio, da educação especial e dos anos finais do ensino fundamental, na modalidade profissional da educação de jovens e adultos (BRASIL, 2008).

Além disso, são previstas, também, nesta Lei, em seu artigo 1으, duas modalidades de estágio. O estágio curricular obrigatório em seu $\S 10$, “[...] definido como tal no projeto do curso, cuja carga horária é requisito para aprovação e obtenção de diploma" e o estágio não obrigatório no §2으, "[...] é aquele desenvolvido como atividade opcional, acrescida à carga horária regular e obrigatória" (BRASIL, 2008). De modo particular, o estágio durante a formação acadêmica tem um papel importante para o futuro profissional, seja de forma obrigatória ou não, pois trata-se de um momento em que o discente pode ampliar e problematizar a articulação entre os domínios teóricos e práticos, além de aproximá-lo do espaço profissional. Do contrário torna-se o ato "de tomar os conhecimentos adquiridos na universidade e aplicá-los na escola de educação básica" (CORSO; DIAS, 2019, p. 2) como uma receita.

Com o histórico e as possibilidades, mas também os limites sinalizados por diversas pesquisas a respeito do estágio obrigatório (CARVALHO; ARRUDA, 2008; AGUIAR-JUNIOR, 2009; PIMENTA; LIMA, 2011; LIMA; WIRZBICKI, 2017), nos questionamos sobre as possíveis contribuições do estágio não obrigatório, posto que essa é uma prática corriqueira no contexto escolhido para esta investigação. Com intenção de compreender melhor o alcance e as possibilidade do estágio não obrigatório, recorremos a alguns regulamentos de estágio das universidades públicas da Região Sul do país, uma vez que não identificamos produções acadêmicas a respeito da temática.

A Região Sul do Brasil possui 12 universidades públicas federais. Dessas, seis estão localizadas no Estado do Rio Grande do Sul, duas em Santa Catarina e quatro no Paraná. Nos cursos de licenciatura em Ciências Biológicas, assim como dos demais cursos da mesma instituição, os estágios (obrigatório e não obrigatório) são regulamentados por documentação própria, e inseridos no contexto dos Projetos Pedagógicos dos Cursos (PCC).

Para exemplificar o teor desses regulamentos de estágio, no PPC em Ciências Biológicas, da Universidade Tecnológicas Federal do Paraná (UTFPR) Campus Santa Helena, o estágio obrigatório busca contemplar as diversas faces do processo educativo entre elas a prática da Gestão Escolar, o Planejamento Educacional e a Atuação Profissional e/ou Regência. Dentro deste contexto, o estágio obrigatório de Ciências e de Biologia revelam como objetivo principal a análise da prática docente mediante a observação e intervenção. Ainda, no PPC há a inclusão do estágio não obrigatório como atividade integradora para o enriquecimento curricular, sendo categorizada como ação de um dos grupos de Atividades Complementares de Curso (ACCs). 
O PPC do curso de Ciências Biológicas da Universidade Federal do Paraná (UFPR) designa o estágio curricular obrigatório como um processo de construção e reconstrução do conhecimento articulado com a realidade, buscando autonomia profissional do aluno, sendo uma produção coletiva que envolve tanto os estudantes quanto os professores, bem como os profissionais onde o estágio é realizado. No mesmo documento, a atividade de estágio não obrigatório é citada como uma das ações formativas relacionadas ao ensino, pesquisa e extensão, de forma a assegurar um caráter interdisciplinar ao acadêmico (UFPR, 2014).

No PPC de Ciências Biológicas da Universidade Federal da Fronteira Sul (UFFS), campus Realeza, o estágio curricular obrigatório é uma prática configurada como uma das atividades mais importantes na formação inicial de professores, estabelecendo a relação entre a teoria e a prática social, oferecendo aos licenciandos a oportunidade de vivenciar situações reais de trabalho. As ações realizadas no estágio não obrigatório fazem parte de uma lista com outras 16 atividades apontadas também como ACCs, e que reúne ações que tenham como propósito a iniciação científica, tecnológica e de formação profissional (UFFS, 2012).

Na Universidade Federal de Santa Catarina (UFSC), o PPC de Ciências Biológicas demonstra uma preocupação com a realização do estágio não obrigatório, ao citar as condições exigidas para que haja a realização desta atividade. Sinaliza o período para que seja realizado e quais os requisitos para que a validação da atividade contribua no currículo do aluno, indicando a necessidade de apresentação dos relatórios.

De acordo com o PPC de Ciências Biológicas, da Universidade Federal de Pelotas (UFPEL), o estágio não obrigatório compreende o desenvolvimento de ações não obrigatórias e de inserção no mundo do trabalho, cuja carga horária não interfira no desenvolvimento das demais exigências da graduação.

Com o que é citado nos PPCs, os estágios (obrigatório e não obrigatório) podem ser processos de construção e reconstrução do conhecimento articulado com a realidade, e corroboram com a promoção da interdisciplinaridade e da autonomia profissional do acadêmico. Diante disso, o estágio obrigatório e nãoobrigatório pode ser uma ação coletiva e participativa, envolvendo os professores e alunos da educação básica, ou os funcionários de uma empresa, servidores do curso de graduação, além dos supervisionares e orientadores. Isso porque a formação do profissional para todas as áreas não se limita às atividades científicas e teóricas realizadas no decorrer do curso de graduação, mas em conjunto com a formação que é possibilitada a partir das ações realizadas no campo de estágio. 0 contato com os diferentes espaços e ambientes formativos possibilita aos acadêmicos reflexões sobre a natureza e a especificidade do seu trabalho profissional, delineado por um conjunto de elementos teóricos, epistemológicos e metodológicos. Esse conjunto de saberes pode viabilizar a apropriação e mobilização do conhecimento científico aos diferentes grupos que permeiam o espaço de aprendizagem da profissão.

No entanto, e de modo específico, no que diz respeito ao estágio não obrigatório, as informações apresentadas nos PPCs dos respectivos regulamentos de estágio ainda são vagas, o que pode ser um reflexo da ausência de informações e orientações nas legislações educacionais. Ou seja, compreendemos que em 
ambas as situações há pouco reconhecimento das contribuições do estágio não obrigatório à formação acadêmica e profissional dos envolvidos.

\section{METODOLOGIA DE PESQUISA}

No contexto das pesquisas educacionais historicamente há um dilema quanto encaminhamentos metodológicos de natureza qualitativa e quantitativa. No entanto, ancorados na proposta de Lüdke e André (1986) justificamos o domínio qualitativo por compreendermos que o pesquisador tem um contato direto e estreito com a situação, a alteração dos fenômenos ocorre de forma natural e são influenciados diretamente pelo contexto no qual estão inseridos.

Ainda na pesquisa qualitativa há diferentes métodos para o desenvolvimento das investigações. Entre eles o "Estudo de caso". Para Lüdke e André (1986), este método requer interpretações de um contexto de pesquisa e busca relatar a realidade de alguma situação, bem como representa os diferentes pontos de vista quanto a uma situação social. Posto isso, a pesquisa foi realizada no contexto do curso de Licenciatura em Ciências Biológicas da UFFS, no Campus Realeza, com os egressos e acadêmicos que desenvolveram atividades de estágio não obrigatório.

Os dados empíricos da pesquisa foram produzidos a partir de uma análise documental realizada nos Planos de Atividades (PA) de Estágio Não Obrigatório e nos Relatórios Finais (RF) de Estágio. A partir do material obtido identificamos a presença de 30 acadêmicos, sendo sete deles concluintes e 23 em processo de formação inicial, no período em que a pesquisa foi realizada (2019).

Posto isto, realizamos a análise dos documentos disponibilizados pelo setor de estágios. Levamos em consideração que o período de vigência de cada estagiário poderia ser de até 2 anos. É importante sinalizar que havia a possibilidade de que as atividades fossem realizadas em locais diferentes, sem exigências de fazê-lo no mesmo espaço.

As informações obtidas foram analisadas a partir da Análise Textual Discursiva (ATD), que é um processo que se inicia com uma unitarização, quando os textos são separados em unidades de significado. Neste movimento de interpretação do significado, como descrito por Moraes e Galiazzi (2006), exercita-se a apropriação das palavras de outras vozes para compreender melhor o texto. Depois disso, são reunidos e articulados os excertos com significados semelhantes em um processo denominado de categorização, que pode gerar vários níveis de categorias de análise.

Para os autores, a ATD é uma ferramenta mediadora na produção de significados e, por isso, em processos recursivos a análise somente pode ser alcançada se o pesquisador fizer um movimento intenso de interpretação e produção de argumentos (MORAES; GALIAZZI, 2006). Assim, com o uso da ATD identificamos excertos que, no nosso entendimento, revelam as atividades, lacunas e contribuições do estágio não obrigatório à formação de profissionais da Licenciatura.

Seguindo os preceitos da ATD, analisamos 30 Planos de Atividades (identificados como PA) e 20 Relatórios finais (RF) de Estágio Não Obrigatório. Nos PAs analisamos os objetivos gerais e específicos construídos pelos estagiários e, na 
sequência, as atividades que seriam realizadas. Por sua vez, nos RFs foram selecionados e analisados os itens referentes às atividades realizadas, às contribuições e às dificuldades apresentadas pelos estagiários. Na análise dos documentos os nomes dos autores foram substituídos pela letra " $P$ " (participantes), seguidos de um número algébrico, formando o seguinte par: P1, $\mathrm{P} 2$, até $\mathrm{P} 30$.

Antes da apresentação e da discussão das categorias é importante sinalizar que, segundo os PAs, as atividades de estágio não obrigatório foram realizadas em espaços formais de educação, sendo que 11 participantes realizaram suas atividades em escolas de Educação Infantil e outros 15, em escolas de Ensino Fundamental. E em outros espaços, dentre quatro participantes, um desenvolveu o estágio em um laboratório de análises clínicas; um em uma Empresa de Projetos Ambientais, o terceiro em um Programa de Agentes Comunitários de Saúde; e o último, fez seu estágio não obrigatório junto ao Serviço de Assistência Social. No quadro 01 apresentamos a relação dos participantes com o local de desenvolvimento das atividades de estágio não obrigatório.

Quadro 1 - Relação de locais/áreas de estágio não obrigatório

\begin{tabular}{|c|c|}
\hline $\begin{array}{c}\text { Estagiários Não } \\
\text { Obrigatórios } \\
\begin{array}{c}\text { P2-P3-P4-P5-P6- } \\
\text { P26-P13-P24- }\end{array}\end{array}$ & Local de Atividade \\
\hline $\begin{array}{c}\text { P10-P11-P12-P14- } \\
\text { P15-P16-P17-P19- } \\
\text { P21-P22-P23-P25- } \\
-P 27-P 29-P 30\end{array}$ & Escolas de Ensino Fundamental \\
\hline P8 & Laboratório de Análises Clínicas \\
\hline P20 & Empresa de Projetos Ambientais \\
\hline P18 & Programa de Agentes Comunitários de Saúde \\
\hline P1 & Assistência Social- Associação Angélica Bilo de \\
\hline
\end{tabular}

Fonte: Autoria própria (2019).

Para finalizar esta seção, informamos que o projeto de pesquisa que originou este artigo foi avaliado pelo Comitê de Ética na Pesquisa (CEP/UFFS) e aprovado com o número de parecer 3.066.965, na data de 08 de dezembro de 2018.

\section{RESULTADOS E DISCUSSÕES}

Após intensas e frequentes leituras do material, unitarização e identificação das unidades de significado, interpretação e categorização, identificamos duas principais categorias de análise. A primeira categoria, "O perfil do licenciado em Ciências Biológicas e suas atribuições no estágio não obrigatório", reúne duas subcategorias: "Atividades correspondentes ao perfil do egresso em Ciências Biológicas e atividades não compatíveis com a formação do curso de Ciências Biológicas". A segunda categoria, "Contribuições do estágio não obrigatório para a formação do licenciado em Ciências Biológicas", emergiu das categorias 
intermediárias "Experiência profissional e Identidade profissional docente". A apresentação, interpretação e análise realizadas com as informações obtidas e que correspondem às categorias citadas, são exploradas na sequência.

\section{O PERFIL DO LICENCIADO EM CIÊNCIAS BIOLÓGICAS E SUAS ATRIBUIÇÕES NO ESTÁGIO NÃO OBRIGATÓRIO}

O curso de graduação em Ciências Biológicas, da UFFS - campus Realeza, lócus desta investigação, também foi explorado nas pesquisas de doutorado realizadas por Hoffman (2016) e Lima (2019). No primeiro caso a autora investigou as potencialidades da Intercoletividade na constituição da identidade profissional de docentes do Ensino Superior do curso de licenciatura em Ciências Biológica. Enquanto Lima (2019) analisou como os princípios formadores estabelecidos pela legislação nacional, da instituição e do curso de Ciências Biológicas, foram mobilizados e contemplados na formação dos seus acadêmicos. Nos dois casos as autoras sinalizam a importância de realizar investigações em espaço como esses, uma vez que o citado curso foi criado em 2012.

Entre as justificativas apresentadas para sua criação foram apresentados argumentos relacionados à questão geográfica da universidade, uma vez que o campus está localizado distante dos grandes centros, e a mesorregião do sudoeste do Paraná possui 37 municípios. Ou seja, a UFFS tem uma importância regional muito expressiva e pertinente para o acesso ao ensino superior, uma vez que é histórica e pertinente as lacunas e carências de cursos de licenciatura em instituições públicas na região, "[...] não só na região sudoeste do estado, mas também em outras regiões do Brasil [...]" (UFFS/PPC, 2012, p. 21-22).

$\mathrm{Na}$ organização curricular dos PPC, a instituição preconiza por um "[...] currículo em torno de um tronco universal, a partir de três domínios: Domínio Comum; Domínio Conexo; e Domínio Específico." (PPI, 2010, s.p). Essa estrutura tem como objetivo a promoção de uma formação crítica, social, interdisciplinar e profissional. Segundo a UFFS, a organização nesses três domínios otimiza a oferta de disciplinas e amplia as oportunidades de acesso e inserção à comunidade. Tais objetivos e orientação não são novos e nem exclusivos da UFFS, eles atendem às referências nacionais para os cursos de graduação, de modo geral, como também as diretrizes voltadas à formação de professores.

Mediante a sua organização curricular, o PPC de Ciências Biológicas apresenta como atribuição profissional dos seus egressos:

\footnotetext{
Atuar na formação inicial e continuada em Ciências Biológicas e de professores do Ensino Fundamental e Médio; Possuir uma visão transdisciplinar e integrada das Ciências Biológicas,[...]; Atuar como professor de Ciências do Ensino Fundamental e de Biologia no Ensino Médio em todos os espaços e ambientes da educação formal ou não formal [...]; Portar-se como educador consciente de seu papel na formação de cidadãos, inclusive na perspectiva socioambiental[...]; Utilizar dos conhecimentos da Ciência básica e aplicada e suas tecnologias, bem como das ciências humanas e sociais como referências e instrumentos para o ensino formal e para a condução de situações educativas ambientais e gerais; [...] Realizar o planejamento e o desenvolvimento de diferentes experimentos didáticos em Biologia, reconhecendo os elementos importantes e as estratégias adequadas para um ensino significativo;[...] (UFFS, 2012 p. 29).
} 
Além das possibilidades para atuação profissional em espaços formais de educação, segundo consta no PPC o egresso também poderá atuar nas áreas previstas pela lei que regulamenta a profissão do Biólogo Bacharel (Lei 6684, de 03/09/1979). E independente da atuação e inserção profissional defende-se uma formação ampla e generalista, que atenda à legislação vigente a respeito dos conteúdos específicos e que esses estejam relacionados aos conhecimentos educacionais e pedagógicos.

No entanto, Lima (2019) identificou que alguns princípios institucionais não foram contemplados na formação dos acadêmicos e entre eles, o trabalho sobre as diferentes possibilidades profissionais foi uma lacuna identificada na formação dos egressos.

Assim, diante das atribuições e possibilidades profissionais do licenciando e do licenciado em Ciências Biológicas, analisamos as atividades do estágio não obrigatório, apresentadas no PA e com isso identificamos as "atividades correspondentes ao perfil do egresso em Ciências Biológicas" e "atividades não compatíveis com a formação do curso de Ciências Biológicas", subcategorias, discutidas na sequência.

\section{Atividades correspondentes ao perfil do egresso em Ciências Biológicas}

Esta subcategoria emergiu a partir de relatos semelhantes apresentados por participantes que realizaram o estágio não obrigatório em espaços formais de educação (Centros Municipais de Educação Infantil- CMEI e nas Escolas de Ensino Fundamental). P3, que sinaliza como atividade o "desenvolvimento da autonomia, identidade, comunicação e linguagens, além de brincadeiras lúdicas que estimulem o desenvolvimento psicológico e cognitivo", bem como a descrição de atividades do P12, em que as ações seriam realizadas de modo a "desenvolver atividades e conteúdos que forneçam às crianças diversos conhecimentos do meio em que vivemos, acompanhados de atividades lúdicas e desenvolvimento de oficinas com os alunos". Dentro deste mesmo contexto, uma das descrições de atividades que chamou a atenção durante a análise dos dados foi a do P21, que apontou o ato de "ministrar aula de Ciências", quando a descrição foi especificamente aos conteúdos exigidos pelo Projeto Político Pedagógico da escola em que ele realizou o estágio não obrigatório.

De modo geral, nas análises dos PAs do P9, P13 e P26, observamos a descrição de algumas atividades direcionadas para o desenvolvimento humano, o relacionamento em sociedade e de ações que promovam a identidade e a formação pessoal e profissional. Outra observação foi em relação às atividades do P14, que listou como ações a "elaboração de materiais didáticos; experimentação ou atividades práticas; construção de terrário e filmes relacionados a Ciências".

Nos demais espaços de formação profissional, P20 por realizar o estágio não obrigatório em uma Empresa de Projetos Ambientais, destaca que as atividades a serem realizadas em uma empresa de projetos sustentáveis incluiriam: "acompanhamento do licenciamento ambiental e dos planos e programas da Usina Hidrelétrica (UHE) Baixo Iguaçu, bem como realizar registros de documentação necessária e auxiliar nos trabalhos de rotina da equipe". O P8, que atuou em um 
laboratório de análises clínicas, listou como ações a "realização de exames, triagem de dados dos pacientes e auxílio na realização de exames laboratoriais".

Neste contexto, os estágios, junto a outras atividades acadêmicas e profissionais, têm como objetivo estimular a interação entre o domínio teórico e prático da formação. Ao observarmos as atividades realizadas nos estágios não obrigatórios, reafirmamos essa perspectiva. Para Scalabrin e Molinari (2013), quando o acadêmico tem contato com as atividades que o estágio lhe oportuniza, inicia a compreensão daquilo que tem estudado e começa a fazer a relação com o cotidiano do seu trabalho. Somado a isso, enfatizamos, em concordância às autoras, que o aprendizado é mais significativo quando obtido junto ao domínio prático do conhecimento.

Com o desenvolvimento das atividades previstas nos PAs, e outras decorrentes do próprio espaço de atuação, os estagiários registraram em seus RFs alguns desafios encontrados durante o trabalho e, entre eles, destacamos: o mau comportamento e o desinteresse dos alunos. A presença de alunos com algum tipo de dificuldade de aprendizagem também foi encontrada e vivenciada pelos estagiários.

Para exemplificar essas dificuldades vivenciadas pelos participantes que atuavam em espaços formais de educação, destacamos o excerto do P24, ao relatar a "desobediência, momentos de dispersão da turma com conversas paralelas e o uso de castigos em situações assim; dificuldades para realizar atividades por falta de recurso ou materiais", assim como o relato do P25: "a maior dificuldade enfrentada foi a bagunça, a desobediência, a falta de respeito e o desinteresse dos alunos durante as oficinas", e do P28, que diz ter tido dificuldade na "interação com alguns pais, o convívio com alguns colegas de trabalho, a falta de limite e respeito de algumas crianças".

A partir de situações desta natureza, torna-se importante que os professores tenham formação e acompanhamento permanente para analisar, compreender, discutir e atender às peculiaridades apresentadas pelos alunos. O P14 e o P24 registraram que houve uma participação e colaboração da escola diante dessas situações, o que é muito importante e significativo na formação inicial de professores e gestores, uma vez que eles desempenham papéis específicos dentro do contexto escolar.

Com esses e outros excertos emerge a interação ou a falta dela entre professores e alunos. Lopes (2009) afirma que em todo processo de aprendizagem humana a interação social e a mediação do outro tem fundamental importância; assim, a interação professor-aluno é imprescindível para que ocorra o sucesso no processo de ensino e aprendizagem. Desta maneira, quanto mais o professor compreender a dimensão do diálogo como atitude importante em suas aulas, maiores avanços serão conquistados em relação aos alunos, pois, desse modo, sentir-se-ão mais curiosos e mobilizados para transformar a realidade.

Além disso, a escola pode criar um ambiente mais estimulante e afetivo que possibilite a esse adolescente enxergar-se no processo e no contexto. A mediação do professor contribui para a construção do conhecimento pelo aluno. Destacamos, a partir de Lopes (2009), que construir uma relação professor-aluno baseada no afeto, não pode ser confundida com permissividade, pelo contrário, 
[...] a ação do professor deve impor limites e possibilidades aos alunos, fazendo com que estes percebam o professor como alguém que, além de lhe transmitir conhecimentos e preocupar-se com a apropriação dos mesmos, compromete-se com a ação que realiza, percebendo o aluno como um ser importante, dotado de ideias, sentimentos, emoções e expressões (LOPES, 2009. p. 7).

Neste contexto, o professor, ao atuar como um mediador, é capaz de articular as experiências dos alunos com o mundo, levando-os a refletir sobre seu entorno, não se limitando somente a transmitir conhecimento, mas, sim, envolvendo-os numa relação de aprendizado e que poderá minimizar o comportamento inadequado dos alunos.

Mesmo que os estagiários tenham se deparado com situações desafiadoras junto as turmas que atuavam, essas vivências fazem parte do cotidiano escolar, que será campo de atuação dos futuros docentes.

\section{Atividades não compatíveis com a formação do curso de Ciências Biológicas}

$\mathrm{Na}$ segunda subcategoria, reunimos aquelas atividades que não são compatíveis ou adequadas com a formação propiciada pelo curso a partir do perfil profissional dos egressos. Entre elas está a realização de atividades que incluem cuidados pessoais com as crianças. As atividades, realizadas nos espaços formais de educação, como no CMEl e nas Escolas de Ensino Fundamental, e direcionadas aos cuidados pessoais foram identificadas em nove dos 30 PA. A seguir, alguns excertos que exemplificam essas atividades: segundo o P5, as ações a serem realizadas incluiriam "auxiliar na alimentação, troca de fraldas e de roupas; auxiliar na hora do sono"; para o P7, a realização de "auxílio da alimentação e trocas de fraldas"; e conforme o P24, que auxiliaria no "acolhimento das crianças, cuidados e alimentação".

Dos 30 estagiários, 11 realizaram as atividades do estágio não obrigatório na Educação Infantil a partir das parcerias com os municípios. Compreendemos, no entanto, que neste contexto, se

[...] integram as funções de educar e cuidar, comprometidas com o desenvolvimento integral da criança nos aspectos físico, intelectual, afetivo e social, compreendendo a criança como um ser total, completo, que aprende a ser e conviver consigo mesma, com o seu semelhante e com o ambiente que a cerca (R.; T., 2012, p. 4)

Para enfatizar isso, as autoras afirmam que não é possível trabalhar a concepção de cuidar e educar dicotomicamente, uma vez que em todos os processos e ações da rotina escolar a criança está inserida em constante aprendizado e, por este motivo, é importante que haja um bom planejamento por parte de quem está educando (R.; T., 2012). Nesse sentido, o curso de Licenciatura em Ciências Biológicas, ao qual pertencem os participantes, não aborda em seus componentes curriculares discussões como essas. Compreendemos, dessa forma, que entre o cuidar e o educar compete aos estagiários, também, o ato de cuidar, ação incompatível com a sua formação inicial.

Em análise dos RFs, um dos itens está relacionado às dificuldades e desafios referentes ao desenvolvimento das atividades de estágio. Entre elas as atividades 
incompatíveis com a formação acadêmica se fazem presentes. Identificamos em alguns RFs que as atividades que não correspondiam com a sua formação acadêmica impactaram de modo significativo no desenvolvimento do trabalho. Assim, ressaltamos os relatos do P15, que diz: "acredito que a oficina a ser trabalhada deveria ser voltada à área de formação do estagiário"; e do P12, que enfatiza o desafio que teve "tendo que preparar aulas e dinâmicas que chamem a atenção dos alunos; como as oficinas não são trabalhadas durante a Graduação, estas acabam se tornando um desafio para quem estará atuando como professor".

Dentro deste contexto ainda observamos os relatos do P8, P18 e P20, que realizaram o estágio não obrigatório em espaços que não são escolares - o primeiro no Laboratório de Análises Clínicas, o segundo em um Programa de Agentes Comunitários de Saúde e o último, em uma Empresa de Projetos Ambientais. $\mathrm{Na}$ análise documental do RF do P8 e do P20 não foram apresentadas as dificuldades ou contribuições com a prática do estágio não obrigatório. Já no RF do P18, que havia realizado atividades de Agente Comunitário de Saúde, "a maior dificuldade enfrentada foi em relação à população, muitas vezes despreparada, que não consegue perceber que nosso objetivo é melhorar sua própria vida social". Assim, mesmo que seja fora do contexto escolar, inferimos que essa dificuldade apresentada pelo participante se relaciona com a participação do público-alvo, chamando atenção para que o envolvimento seja mais significativo.

Há, portanto, uma situação a ser analisada pela instituição cedente, na qual professor orientador e supervisor visam a adequação das atividades centrais a serem realizadas pelos estagiários, corroborando com um desenvolvimento de qualidade nas ações. Além disso, compreendemos que o trabalho do professor com formação em Pedagogia, pré-requisito para trabalhar na Educação Infantil, pode ser valorizado junto as Secretarias de Educação, pois são eles os profissionais habilitados para realizar o trabalho com as crianças em fase inicial. Porém, o fato de a inserção dos acadêmicos ser em atividades adequadas ou não, contribuiu para a formação dos envolvidos?

Ainda que a atividade central não seja adequada ao perfil formativo dos estagiários, inferimos, inicialmente, que a inserção deles em espaços formais de educação possibilita a vivência de uma realidade educacional e a oportunidade de criar experiências sobre situações do cotidiano escolar, desde que eles reconheçam as experiências do professor da turma e realizem com eles a indagação e a investigação sobre os eventos planejados e realizados na sala de aula.

Por isso, é importante permitir que os acadêmicos tenham noção do contexto escolar desde o início de sua formação; assim, quando inseridos no cotidiano da escola, passam a ter a real noção do que irão enfrentar na sua profissão. Desse modo, a experiência do estágio não obrigatório para os participantes representa um importante momento para sua formação profissional, mesmo com todas as características e dificuldades presentes; afinal, o estágio é um momento de observação, problematização, reflexão e aprendizagem a respeito do exercício profissional, o que fomenta contribuições importantes na formação do licenciado em Ciências Biológicas, como destacamos a seguir. 


\section{CONTRIBUIÇÕES DO ESTÁGIO NÃO OBRIGATÓRIO PARA A FORMAÇÃO DO LICENCIADO EM CIÊNCIAS BIOLÓGICAS}

Após um ciclo de atividades realizadas no campo de estágio, os estagiários entregam um relatório descrevendo as atividades desenvolvidas e como elas podem ter contribuído para sua formação acadêmica e profissional. Dessa leitura emergiu um conjunto de argumentos e possibilidades que foram reunidos em duas principais subcategorias: experiência profissional e identidade profissional docente.

\section{Experiência Profissional}

Verificamos que quando os estagiários relatam sobre as contribuições que a prática do estágio não obrigatório proporcionou a eles, o principal apontamento está relacionado à experiência profissional que foi construída mediante o desenvolvimento das atividades. Dos $20 \mathrm{RFs}$ analisados, cinco deles sinalizam que a troca de experiências dentro do ambiente escolar, tanto com os professores quanto com os alunos, foi uma das situações que mais contribuíram na construção dessa experiência. Neste sentido, no relato do P22 há a afirmação de que com o estágio ela pode "aprender a agir diante das diversas situações comportamentais e pedagógicas, aprimorando o desenvolvimento de competências e habilidades, bem como a postura de profissional". O P24 reafirma o momento de estágio como a possibilidade de "reconhecer e aplicar diferentes formas de conduzir uma aula e aprender com a professora supervisora como avaliar os alunos"; este mesmo participante ainda destaca que em vários momentos presenciou situações que "enriquecem a minha visão da docência e atuação como profissional".

Assim, a realização dos estágios, bem como outras atividades acadêmicas ou profissionais, estimulam a relação entre o domínio teórico e prático durante a formação de um profissional. Neste contexto, quando voltamos nosso olhar às atividades realizadas nos estágios não obrigatórios, reafirmamos a perspectiva de Scalabrin e Molinari (2013), que salienta que o contato do acadêmico com às atividades de estágio oportuniza o início da compreensão do que havia sido estudado com relação ao dia a dia, deixando evidente que o aprendizado é muito eficiente quando assimilado a partir de experiências.

Nessa situação, o que existe é a articulação entre os diferentes saberes da profissão, aqueles relacionados com os conteúdos específicos do curso de Ciências Biológicas e com os conteúdos abordados no ambiente de estágio. Ainda, com as atividades desenvolvidas no estágio, os estagiários puderam compreender e respeitar melhor as particularidades de cada indivíduo, o tempo e a personalidade de cada aluno. Neste contexto, o P15 elenca como uma contribuição a

\footnotetext{
oportunidade de aprender sobre o respeito que devemos ter frente às particularidades de cada cidadão, seus tempos, limites e personalidades; foi possível compreender o funcionamento do meio escolar, bem como a prática pedagógica docente, relacionando a teoria trabalhada em sala de aula com a prática; foi possível colocar em prática os conhecimentos aprendidos em aula, entre eles a importância do planejamento das atividades, do lúdico em sala e trabalhos em grupo, a importância de considerar e respeitar as certos temas.
} 
Na mesma perspectiva, P23 por realizar o estágio não obrigatório em uma escola de Ensino Fundamental enfatiza que a "experiência da docência em sala de aula com realidades distintas de cada turma e o processo de aproveitamento e crescimento intelectual de cada aluno" é uma experiência importante para sua formação acadêmica e profissional.

São depoimentos ricos em conhecimentos e experiências sobre aquilo que compõe o espaço escolar: relações entre saberes, relações humanas, subjetividades, estratégias de ensino, experiência. Com esses relatos observamos e concordamos com o que afirma Lopes (2009), que em todo processo de aprendizagem humana a interação social e a mediação do outro têm fundamental importância; assim, no ambiente escolar a interação professor-aluno é imprescindível para que ocorra o sucesso no processo de ensino e aprendizagem. Quando a abordagem do professor se dá com um processo de interação, não se está pensando em um lugar onde cada um faz o que quer, mas em um espaço de construção, de valorização e respeito, no qual todos se sintam mobilizados a pensar em conjunto.

Em suma, na abordagem do professor é importante a realização e interação dos conteúdos específicos do curso. A prática dos estágios não obrigatórios também pode ser ressaltada nesses momentos de formação. Esse movimento, proporcionado pelos estágios não obrigatórios, são momentos que possibilitam a interlocução entre o espaço de formação institucional e o campo de atuação profissional. Em outras palavras, o estágio foi experienciado como espaço para articular a teoria e a prática relativa à docência (SILVA; GASPAR, 2018).

Quando abordamos os saberes docentes, relembramos o apontamento de Tardif (2012), de que a relação dos docentes com os saberes não se reduz a uma função de transmissão dos conhecimentos já constituídos; essa prática integra diferentes saberes. Nesse sentido, pode-se definir o saber docente "como um saber plural formado [...] de saberes oriundos da formação profissional e de saberes disciplinares, curriculares e experienciais" (TARDIF, 2012, p. 36).

Os saberes experienciais, como sinalizados por Tardif (2012), surgem baseados em seu trabalho cotidiano e no conhecimento de seu meio; eles vêm da experiência e são por ela validados. Desse modo, eles incorporam-se à experiência individual e coletiva sob a forma de habilidades, de saber-fazer e de saber-ser. Por isso compreendemos que, com as atividades, os estagiários podem ter desenvolvido e adquirido saberes relacionados à docência e que contribuirão na sua futura atuação.

\section{Identidade Profissional Docente}

Segundo os estagiários, como consequência da experiência profissional há a construção da identidade profissional docente. Em cinco relatórios encontramos apontamentos sobre a identificação com a docência, o interesse com o ser professor e sobre o ambiente em que se trabalha. O P14 sinaliza em sua prática a possibilidade das "trocas de experiências proporcionando uma identidade docente".

Já o P26, demonstra que durante a realização dos estágios não obrigatórios houve momentos em que "pode-se vivenciar experiências marcantes que 
certamente serão levadas para um futuro profissional", e o P28 descreve que os momentos de estágio "foram de grande importância para minha carreira profissional e também para minha formação acadêmica, dando ênfase na experiência em sala de aula que me fez apreciar ainda mais a licenciatura e o papel importante do professor em sala de aula".

Construir a identidade profissional é algo intrínseco em todas as profissões, inclusive na formação do professor de Ciências e Biologia, que, segundo Cerqueira e Cardoso (2010), tem um mercado profissional relativamente diverso. Ao longo dos anos o professor em formação busca inteirar-se de metodologias que possam melhorar suas práticas, mas isso não se constitui de uma tarefa fácil, pois os licenciandos têm dilemas e dúvidas a respeito da profissão tanto quanto os professores com anos de carreira (CERQUEIRA; CARDOSO, 2010).

Além disso, a identidade docente é "construída ao longo da prática profissional e permeada por influências de familiares, pelas relações interpessoais, por questões culturais, étnicas, papéis sociais e ideologias presentes no contexto em que os professores estão inseridos" (ARRUDA; TEIXEIRA; SILVA, 2015 p. 22.745). Com isso, podemos inferir que a identidade docente é uma construção progressiva e versátil que pode ser influenciada por diversos fatores, sejam estes de ordem pessoal e/ou sociocultural. Assim, cada momento apontado pelos participantes durante a realização dos estágios não obrigatórios corroboraram a construção da sua identidade profissional mediante as experiências e vivências dentro do ambiente escolar.

Sabemos que as atuações formativas adquirem uma importância e uma função imprescindível no desenvolvimento docente. Deste modo, salientamos que o estágio é um campo de conhecimento e de aproximação do estagiário com a profissão que irá exercer, bem como com as pessoas com quem irá trabalhar suas práticas a cada dia, para que consiga ter discernimento para situações de dificuldades futuras.

Os estagiários ainda relataram que com as atividades realizadas nos espaços formais de ensino e com as vivências, foi possível compreender a necessidade de que o profissional continue se aperfeiçoando mesmo após formado, e que busque por melhorias nas metodologias utilizadas e nos conteúdos trabalhados. Ainda, nesse movimento, puderam reconhecer as contribuições da escola como coformadora dos futuros profissionais da docência. Neste contexto, o P10 e o P15 relatam que em vários momentos tiveram o apoio da escola em situações que não sabiam como atuar. Observamos no RF do P14 o relato de que a escola se mostrou favorável às práticas realizadas e deu suporte para que o estagiário conseguisse trabalhar e atender às necessidades de um aluno com a síndrome de Asperger, e no relato o estagiário enfatiza como foi importante o suporte que a escola deu diante desta situação.

Quando voltamos nosso olhar para a formação continuada relatada pelos participantes, salientamos o depoimento de P25 ao afirmar que: "com o estágio percebi que não estamos $100 \%$ preparados para a sala de aula e que nunca estaremos preparados, pois cada dia é diferente, é um fato novo, uma situação nova, é uma realidade diferente que temos que lidar e isso só fez reforçar meus valores sociais, éticos e educacionais". Com esse e outros excertos semelhantes, os estagiários expressam a importância do professor estar em formações 
constantes, atualizando e incorporando novos e outros conhecimentos a suas práticas pedagógicas. Posto isto, assim como Solarevicz (2019), acreditamos que a contemporaneidade exige mudanças, adaptações, atualizações e aperfeiçoamento; assim, a evolução moderna é um desafio para quem se formou há mais de uma década, o que precisa ser compreendido pelos futuros professores.

\section{CONSIDERAÇÕES FINAIS}

Os estágios no período de Graduação podem assumir dois formatos - um obrigatório e curricular e, o outro, não obrigatório, extracurricular -, e, na maioria dos casos, envolvem uma remuneração financeira e uma carga horária semanal de aproximadamente 30 horas. Em um curso noturno, como é o caso do curso de Ciências Biológicas desse estudo, as possibilidades de participar de um estágio não obrigatório são maiores em decorrência do tempo disponível para realizar o trabalho, quando o acadêmico já não está inserido em um ambiente formal de trabalho.

Nesse contexto, não são poucos os acadêmicos que já realizaram ou estão envolvidos com o estágio não obrigatório, e, justamente pela sua expressividade e vivências, é que ele se tornou um campo investigado nesta pesquisa. Nosso trabalho de revisão bibliográfica demonstrou, no entanto, que há poucos trabalhos sobre o assunto, mas uma vasta produção sobre o estágio curricular obrigatório. Por esse motivo é que em vários momentos recorremos à fundamentação teórica ou aos próprios documentos institucionais, que, por sua vez, também silenciam informações a respeito desta atividade, como observado nos documentos analisados das diferentes instituições de Ensino Superior públicas da Região Sul do país.

Diante disso, e movidas pelo interesse em compreender como a prática de estágios não obrigatórios contribui na formação acadêmica e profissional dos licenciandos em Ciências Biológicas, chegamos a duas categorias de análise e aos seguintes questionamentos: a) os estágios não obrigatórios, ao serem silenciados pelas Instituições, tornam-se espaço para o desenvolvimento de diferentes atividades que podem ou não ser compatíveis com a formação acadêmica. Como então torná-la visível?; b) pelo expressivo número de estagiários envolvidos com a Educação Infantil e as séries iniciais do Ensino Fundamental, que são de atribuições do pedagogo, quais são os motivos que levam as Secretarias de Educação Municipal a contratar acadêmicos de cursos que não habilitam formalmente para esse nível de ensino? c) o perfil para os egressos da instituição investigada, mas também recorrente em outras, permite questionar: $\mathrm{O}$ curso de Licenciatura em Ciências Biológicas forma o professor de Ciências e Biologia ou um biólogolicenciado?

Nossos resultados, por sua vez, permitiram compreender que as contribuições do estágio não obrigatório, realizado por acadêmicos do curso de Licenciatura em Ciências Biológica, da UFFS, campus Realeza, pouco se diferem das contribuições já relatadas e historicamente constituídas do estágio obrigatório. Há, no entanto, diferença nos saberes acadêmicos mobilizados e no tempo para desenvolvimento das atividades. Enquanto no estágio obrigatório os saberes acadêmicos específicos de Ciência e Biologia são pensados, planejados e desenvolvidos, no estágio não obrigatório esses saberes podem ser utilizados em momentos muito pontuais e 
com pouco aprofundamento teórico. Em contrapartida, no campo dos saberes didáticos e pedagógicos, o desenvolvimento das atividades realizadas no estágio não obrigatório pode colaborar na articulação entre os domínios teóricos e práticos mediante as discussões, interpretação, apropriação e mobilização dos saberes.

Sobre as semelhanças, ambas envolvem a inserção em um futuro ambiente profissional, o reconhecimento das atividades, possibilidades e dificuldades, a interação entre os saberes acadêmicos, profissionais e experiências e a formação inicial de uma identidade profissional, todas elas possibilitadas, portanto, pelo reconhecimento da realidade profissional, das representações e das práticas dos profissionais.

Em relação ao tempo, a inserção no ambiente escolar, no caso, é parte do componente de estágio obrigatório, realizada habitualmente após a segunda metade do curso e com uma carga horária reduzida. No caso do trabalho em laboratório ou junto as questões ambientais, estão presentes em atividades ainda mais pontuais do currículo acadêmico; situação não enfrentada no estágio não obrigatório - quando os estagiários estão envolvidos diariamente, por até dois anos, em um espaço de atuação profissional convivendo com a complexidade da escola e da comunidade em que está inserido. Neste sentido, Mello (2000) justifica que viver a prática docente é muito importante e válido, desde que a teorização sirva de base para os professores em formação. Saber relacionar os aportes e reflexões teóricas com o exercício da prática docente, pode auxiliar na contextualização dos conteúdos escolares com os fatos reais, (re)construir o significado do conhecimento aprendido e potencializar as suas atividades formativas.

Assim, foi possível perceber o quanto o estágio não obrigatório é utilizado como um movimento de inserção dos licenciandos para contribuir na sua formação, uma vez que essas atividades podem ser realizadas em inúmeras áreas, principalmente quando voltadas para ambientes escolares. Investigar essas atividades, portanto, pode contribuir com os possíveis encaminhamentos das próprias instituições de ensino, bem como dos acadêmicos.

Desse modo, a partir das atividades, dificuldades, desafios e contribuições advindas das práticas de estágio não obrigatório, compreendemos que elas podem ser socializadas junto aos demais acadêmicos do curso de licenciatura em Ciências Biológicas, da UFFS, Campus Realeza, e potencializar uma discussão sobre o espaço social que ele ocupa no PPC de cada curso. O reconhecimento dos valores profissionais do estágio não obrigatório e a socialização das atividades nos componentes curriculares, pode ser uma forma de integrar e discutir as vivências, os saberes envolvidos entre a formação acadêmica e o preparo profissional, para, com isso, ampliar a visibilidade, não apenas do estágio não obrigatório, mas também das políticas educacionais vigentes, como o PIBID e o PRP. Uma articulação entre a universidade e a escola e os saberes teóricos e práticos, poderiam ser potencializadas na formação de professores, a partir dos estágios não obrigatórios. 


\title{
Non-mandatory internship during undergraduate degree in biological science: a space for formative possibility
}

\begin{abstract}
The practice of non-mandatory and mandatory internship is present in several areas of knowledge as it is a means to assimilate the learnt theories that students acquired throughout their formation with the opportunities for professional experiences. The contribution of this kind of experience during academic and professional education of participant students of Biological Science is brought into this research and discussed from start to finish. It was aimed at understanding how the practice of non-mandatory internship may contribute to the academic and professional background of Biological Science students. This research being qualitative, developed from a case study and analysis based on Discursive Textual Analysis (ATD) identified two main categories: The first was about the student profile while the second focused on the contribution of internships in students' education. The results obtained indicate similarity with other contributions historically created in non-mandatory internships as this practice is an opportunity to problematize the development of professional knowledge alongside curricular activities in the undergraduate program. Arguments on the need to broaden the discussion about the graduation of teachers adjoining the tutors in the institution, about the space internship represents in the background of academic teaching degrees and the reasons behind the Municipal Education Offices hiring students who are not formally licensed for this level of graduation are discussed in the conclusion. These reflections are believed to be necessary for the academic and professional qualification of undergraduates.
\end{abstract}

KEYWORDS: Degree in Science. Teacher Education. Teacher Professionalization. 


\section{REFERÊNCIAS}

AGUIAR-JUNIOR, O. A ação do professor em sala de aula: identificando desafios contemporâneos à prática docente. In: CUNHA, A. M. de O. et al. Convergências e tensões no campo da formação e do trabalho docente. Belo Horizonte: Autêntica, 2009. p. 238-264.

ARRUDA, K. W. da S.; TEIXEIRA, T. C. da S.; SILVA, F. L. G. R. da. A docência e a construção da identidade profissional dos professores: algumas reflexões. In: CONGRESSO NACIONAL DE EDUCAÇÃO, 12., 2015, Curitiba. Anais [...]. Curitiba: Educere, 2015.

BRASIL. Lei no 11.788, de 25 de setembro de 2008. Dispõe sobre o estágio de estudantes; altera a redação do art. 428 da Consolidação das Leis do Trabalho (CLT). Diário Oficial da União, Brasília, DF, 26 set. 2008.

CARVALHO, M. A. de; ARRUDA, S. de M. Dilemas e dificuldades apontadas pelos estagiários da licenciatura em Física da UEL sobre a Prática de Ensino. In: CONGRESSO NACIONAL DE EDUCAÇÃO DA PUCPR - EDUCERE, 8., CONGRESSO IBERO-AMERICANO SOBRE VIOLÊNCIAS NAS ESCOLAS - CIAVE, 3., 2008, Curitiba. Anais [...] Curitiba-PR, 2008.

CERQUEIRA, S. V. S. de; CARDOSO, L. de R. Biólogo-professor: relação entre expectativas profissionais e concepções em torno da docência para licenciandos em Ciências Biológicas. Contexto \& Educação, ljuí, v. 84, n. 25, p. 143-160, 2013

CONSELHO FEDERAL DE BIOLOGIA. Resolução n. 10, de 5 de julho de 2003. Dispõe sobre as Atividades, Áreas e Subáreas do Conhecimento do Biólogo. Disponível em: https://cfbio.gov.br/2003/07/05/resolucao-cfbio-no-10-de-5-dejulho-de-2003/. Acesso em: 19 set. 2019.

CORSO, B; SOUZA, F. D. O compartilhamento de ações de estágio como espaço de formação inicial para a docência. ACTIO, Curitiba, v. 4, n. 3, p. 1-16, 2019. Disponível em: https://periodicos.utfpr.edu.br/actio/article/view/9353/6822. Acesso em: 01 mai. 2020.

CORTE, A. C. D.; LEMKE, C. K. O estágio supervisionado e sua importância para a formação docente frente aos novos desafios de ensinar. CONGRESSO NACIONAL DE EDUCAÇÃO, 12., 2015, Curitiba. Anais [...]. Curitiba: Educere, 2015.

CNE. Conselho Nacional de Educação. Resolução CNE/CP 2, de 19 de fevereiro de 2002. Institui a duração e a carga horária dos cursos de licenciatura, de graduação plena, de formação de professores da Educação Básica em nível superior. Disponível em:

http://portal.mec.gov.br/cne/arquivos/pdf/CP022002.pdf. Acesso em: 3 out. 2018.

GHEDIN, E.; ALMEIDA, M. I. de; LEITE, Y. U. F. Formação de professores: caminhos e descaminhos da prática. Brasília: Líber Livro Editora, 2008. 
LIMA, B. G. T.; WIRZBICKI, S. M. Inquietações problematizadas pelo exercício do estágio supervisionado em Ciências. In: ENCONTRO NACIONAL DE PESQUISA EM EDUCAÇÃO EM CIÊNCIAS, - ENPEC, 11., 2017, Florianópolis. Anais [...].

Florianópolis, 2017.

LOPES, R. de C. S. A relação professor aluno e o processo ensino aprendizagem. 2009. Disponível em:

http://www.diaadiaeducacao.pr.gov.br/portals/pde/arquivos/1534-8.pdf. Acesso em: 19 out. 2019.

LÜDKE, M.; ANDRÉ, M. E. D. A. Pesquisa em educação: abordagens qualitativas. São Paulo: Editora Pedagógica e Universitária, 1986. 99p.

MELLO, G. N. de. Formação inicial de professores para a educação básica: uma (re)visão radical. São Paulo em Perspectiva, [s.I.]: FapUNIFESP, v. 14, n. 1, p. 98 110, mar. 2000.

MORAES, R.; GALIAZZI, M. do C. Análise textual discursiva: processo reconstrutivo de múltiplas faces. Ciência \& Educação, São Paulo, v. 12, n. 1, p. 117-128, 2006.

NASCIMENTO, R. P. do. Preparando professores para promover a inclusão de alunos com necessidades educacionais especiais. 2009. Disponível em: http://www.diaadiaeducacao.pr.gov.br/portals/pde/arquivos/2496-8.pdf. Acesso em: 26 out. 2019.

PIMENTA, S. G.; LIMA, M. S. L. Estágio e docência. 6. ed. São Paulo: Cortez Editora, 2011.

PIMENTA, S. G. O estágio na formação de professores: unidade entre a teoria e a prática. Caderno de Pesquisa, São Paulo, n. 94, p. 58-73, ago. 1995.

R, A. C. V.; T, F. P. O educar e o cuidar na educação infantil: narrativas de professoras. In: FÓRUM INTERNACIONAL DE PEDAGOGIA, 4., 2012, Paranaíba. Anais [...]. Campina Grande, 2012.

SANTOS, E. A; FREIRE, L. I. F. Planejamento e aprendizagem docente durante o estágio curricular supervisionado. ACTIO, Curitiba, v. 2, n. 1, p. 263-281, 2017. Disponível em: https://periodicos.utfpr.edu.br/actio/article/view/6767/4365\# Acesso em: 01 mai. 2020.

SCALABRIN, I. C.; MOLINARI, A. M. C. A importância da prática do estágio supervisionado nas licenciaturas. Unar, Araras, v. 7, n. 1, p. 1-12, mar. 2013.

SCHWARTZ, M. A. M.; BAPTISTA, N. M. G. A contribuição do estágio supervisionado no desenvolvimento de aptidões e formação de competências. Revista Diálogo Educacional, Curitiba, v. 2, n. 4, p. 105-111, dez. 2001.

SILVA, H. I.; GASPAR, M. Estágio supervisionado: a relação teoria e prática reflexiva na formação de professores do curso de Licenciatura em Pedagogia. 
TARDIF, M. Saberes docentes e formação profissional. 17. ed. Rio de Janeiro: Vozes, 2012.

UFFS. Universidade Federal da Fronteira Sul. Projeto Pedagógico do Curso de Ciências Biológicas - Licenciatura. Realeza, PR, nov. 2012. Disponível em: https://www.uffs.edu.br/atos-normativos/ppc/cccblre/2012-0001. Acesso em: 18 set. 2019.

UFPR. Universidade Federal do Paraná. Projeto Pedagógico com atualizações curso de ciências biológicas modalidades: bacharelado e licenciatura. 2014. Disponível em: http://www.bio.ufpr.br/portal/cbio/wpcontent/uploads/sites/3/2015/03/Projeto-Pedag\%C3\%B3gico-atualizado2014.pdf. Acesso em: 18 set. 2019.

UTFPR. Universidade Tecnológica Federal do Paraná. Projeto Pedagógico de Curso - Licenciatura em Ciências Biológicas do Campus Santa Helena. Santa Helena, PR, 5 out. 2016. Disponível em:

http://portal.utfpr.edu.br/cursos/coordenacoes/graduacao/santa-helena/shlicenciatura-em-ciencias-biologicas/documentos/ppc-ciencias-biologicas-shversao-final-2016.pdf. Acesso em: 18 set. 2019.

Recebido: 01 mar. 2020

Aprovado: 29 mai. 2020

DOI: 10.3895/actio.v5n2.11709

Como citar:

PINHEIRO, J. A. B. da R.; LIMA, B. G. T. de.; WIRZBICKI, S. M.; DEUS, A. F. E. de. O estágio não obrigatório na formação de licenciados em ciências biológicas: um espaço de possibilidade formativa. ACTIO, Curitiba, v. 5, n. 2, p. 1-21, mai./ago. 2020. Disponível em: <https://periodicos.utfpr.edu.br/actio>. Acesso em: XXX

Correspondência:

Jucilaine Araujo Bottega da Rocha Pinheiro

Rua Jacinta Roveda, n.1436, Bairro Santa Bárbara, Capanema, Paraná, Brasil.

Direito autoral: Este artigo está licenciado sob os termos da Licença Creative Commons-Atribuição 4.0

Internacional.

(c) (1) 